\title{
HUMANIDAD CIBORG
}

\author{
JUAN PEDRO NÚÑEZ PARTIDO \\ Universidad Pontificia Comillas (Madrid)
}

\begin{abstract}
RESUMEN: El presente artículo señala los problemas que a nivel psicológico se vislumbran en torno a lo que se conoce como transhumanismo o post humanismo. El futuro de los humanos ciborg con cerebros asistidos por dispositivos de Inteligencia Artificial (I.A.) podría traer algunas consecuencias indeseables. Si atendemos a cómo nos afecta la interacción con los dispositivos y aplicaciones que el mercado actual de I.A. pone a nuestra disposición, muchas de estas consecuencias parecen inevitables. También se señalan otros aspectos que nos preocupan y cuya evolución es más incierta, así como algunas de las consecuencias sociales previsibles.
\end{abstract}

PALABRAS CLAVE: Ciborg; transhumanismo; post humanismo; aspectos psicológicos y consecuencias sociales.

\section{Cyborg Humanity}

ABSTRACT: The present article points out the psychological problems glimpsed around what is known as transhumanism or post humanism. The future of cyborg humans with brains assisted by devices of Artificial Intelligence (Al) could bring some undesirable consequences. If we look at how affects us the interaction with the devices and applications of A.I. that the current market puts at our disposal, many of these consequences seem inevitable. Other aspects that concern us and whose evolution is more uncertain are also pointed out, as well as some of the foreseeable social consequences.

KEY WORDS: Cyborg; transhumanism; post humanism; psychological aspects and social consequences.

Vivimos en la antesala de un futuro de ciencia ficción, los avances en inteligencia artificial (I.A.) son constantes y progresan a tal velocidad que contemplarlos genera vértigo. El concepto de singularidad anuncia un punto de inflexión sin marcha atrás dónde la evolución de las máquinas inteligentes estará controlada por ellas mismas, pues sólo su capacidad de computación tendrá la potencia de cálculo y la velocidad necesarias para diseñar mejoras aprovechando la ingente cantidad de datos que procesarán. Y lo harán a un ritmo endiablado, alcanzando niveles difíciles de «imaginar», entre otras razones, porque ya no será «nuestra imaginación» la encargada de su diseño. $\mathrm{Y}$ el futuro al que los propios seres humanos nos enfrentaremos es lo que se conoce como transhumanismo o post humanismo, donde gracias a la ingeniería genética, los avances médicos especialmente en neurología con la correspondiente incorporación de sistemas artificiales que potencien y mejoren nuestra actividad cerebral, harán de nosotros una «nueva especie», una especie de «súper hombres» a la que algunas de las mentes más privilegiadas del planeta apenas le ponen límites (Kurzweil, 1999, 2005).

Por otro lado, es fácil suponer que no sería raro que parte de estas predicciones fueran algo exageradas, al menos por lo que permiten suponer los logros científicos alcanzados a día de hoy. Tal vez, el futuro sea como los grandes gurús de estas disciplinas anuncian, pero tal vez también haya algo de «marketing» de sí mismos, de sus proyectos e incluso de sus propias empresas e industrias ${ }^{1}$. Sea

\footnotetext{
1 https://es.wikipedia.org/wiki/Raymond_Kurzweil
} 
como fuere nosotros no estamos en disposición de discutir las posibilidades reales de los logros que puedan alcanzarse en el futuro, ni de cual será exactamente el balance final de costes y beneficios que para la humanidad tendrá el desarrollo de las nuevas formas de inteligencia artificial. Asumimos que, sin lugar a dudas, los beneficios serán muchos y también inevitablemente habrá costes, algunos probablemente muy difíciles de valorar desde nuestra perspectiva actual.

Por eso nuestra intención es centrarnos sólo en lo que conocemos, pues algunos hechos son suficientemente significativos como para que les dediquemos cierta reflexión a los mismos. Lo que hoy sabemos de nosotros mismos podría iluminarnos, en alguna medida, sobre ese futuro tan cargado ya de incertidumbres.

\section{El límite de las máouinas}

Ninguno de los conocimientos actuales en todas y cada una de las ramas del saber nos permiten una mínima explicación o conocimiento fiable sobre la naturaleza física de la experiencia consciente y, por tanto, tampoco comprendemos suficientemente bien su relación con la actividad neurológica del cerebro. Por supuesto, esto podría cambiar en cualquier momento dando un giro radical a cualquiera de las afirmaciones que aquí hagamos, pero a día de hoy nuestro nivel de conocimiento al respecto es extremadamente precario. Por esta razón, asumir que en un tiempo razonable las máquinas inteligentes tendrán consciencia como nosotros es obvio que excede los límites de los conocimientos científicos actuales, por lo que entraría en alguna medida en el terreno de la ficción. Otra cosa es la importancia que pueda tener la experiencia consciente como determinante de nuestra actividad psíquica. Si como defienden muchos ésta apenas tuviera relevancia (Chalmers, 1996; Crick, 1994; Dennett, 1991; Searle, 1992) entonces sí que sería más que razonable suponer que las máquinas acabarán siendo muy parecidas a los seres humanos ya que las operaciones computacionales carentes de consciencia es el reino de la I.A. Sobre la importancia de la consciencia para explicar nuestro funcionamiento psíquico ya hemos escrito en el pasado y no queremos repetirnos ahora, pero conviene dejar claro que desde nuestro punto de vista la experiencia consciente no sólo no es irrelevante, sino que es cualitativamente hablando el epicentro sobre el que se configura una parte muy importante de nuestra actividad psíquica y a través de la cual se desarrollan procesos que de otra manera serían inviables, especialmente aquellos que están directamente relacionados con eso que entendemos como «libertad» (Núñez, 2012, 2013, 2014, 2015).

Además, tampoco parece razonable que, a la industria, al mercado, a la sociedad, a usted, le interese una inteligencia artificial que fuera exactamente como un ser humano. Que lo parezca, seguro que sí, hará que se venda mucho más, pero ¿queremos androides que puedan enfadarse, dudar de lo que tienen que hacer, tener intereses propios, desobedecer, luchar por sus derechos, hacer huelgas, comportarse en modo y forma contrarios a los objetivos para los que fueron diseñados y adquiridos? Si la respuesta es negativa, ésa sería otra de 
las razones por las que vemos muy difícil que la I.A. adquiera consciencialibertad. Se puede elucubrar que tal vez ésta sea una consecuencia no deseada ni buscada del híper desarrollo de la inteligencia artificial, una vez ésta haya alcanzado independientemente complejos niveles de evolución. Tal vez, pero es de nuevo un "tal vez» que nos resulta demasiado especulativo, pues que las máquinas sin consciencia busquen y alcancen los conocimientos suficientes para diseñar algo tan desconocido y extraño para ellas como incomprensible para nosotros y que en modo alguno interesa que consigan, parece difícil, al menos a medio plazo.

\section{UNA OFERTA IRRESISTIBLE}

En cambio, sí estamos a las puertas de enfrentarnos a un montón de consecuencias, muchas de ellas negativas y claramente previsibles, en la otra línea de avance del binomio inteligencia artificial-medicina que ya son una realidad. Consecuencias directamente relacionadas con la actividad consciente que, como hemos dicho, para nosotros es central a la hora de entender nuestro funcionamiento psíquico. Nos referimos al fenómeno ciborg, a las prótesis computacionales de alto nivel y de todo tipo que pueden acoplarse e interaccionar directamente con nuestro tejido neuronal. Hoy en día, gracias a ese tipo de prótesis hay personas ciegas que han recuperado la vista, o personas sordas que pueden oír. Se pueden insertar en nuestro cerebro dispositivos que actúen de forma específica y cuando sea necesario sobre determinados centros neuronales para corregir los desequilibrios neuroquímicos responsables de cierta sintomatología. Hay dispositivos que permiten a sus usuarios controlar cerebralmente las prótesis motoras que se les han instalado para sustituir los miembros de los que carecían (manos, brazos, piernas) y que incluso les proporcionan sensaciones propioceptivas...

Todo ello es maravilloso, como maravilloso es internet y lo que ha facilitado nuestras vidas, con todo lo que nos proporciona y lo que la nube supone para nuestro trabajo, ocio, relaciones personales y desempeños cotidianos de todo tipo. E igual de maravilloso es el desarrollo de la realidad virtual que nos permite tener sensaciones conscientes de ilimitadas experiencias sin salir de casa. Como maravillosas son todas las aplicaciones de I.A. que identifican el lenguaje hablado y escrito en cualquier lengua y lo traducen, transcriben y leen con un grado de "comprensión» y precisión casi perfectos. O las distintas aplicaciones que reconocen rostros, lugares, edificios, estados emocionales, síntomas clínicos, patrones estadísticos complejos tanto de la actividad de los mercados como de fenómenos climatológicos..., que razonan, deducen y toman decisiones al nivel de un experto en su campo. Todo esto ya es real y las mejoras son casi diarias.

Cada uno de estos avances han entrado en nuestras vidas invadiéndolo todo y han sido recibidos como grandes éxitos y logros a los que difícilmente nos hemos podido resistir, por eso, del mismo modo hemos de asumir que entrarán y formarán parte de nuestro cerebro las versiones «neurales» de las 
aplicaciones que están por venir y que acabaremos dependiendo de ellas como nunca antes hemos dependido de ningún otro apósito o herramienta externa.

La mayoría de los seres humanos que no utiliza un teléfono móvil es porque no tiene acceso al mismo. El resto de la humanidad ya no discute su uso sino el cuándo considerarlo excesivo y cuánto gastarse en el siguiente modelo, algo que va cambiando a medida que su uso se dispara y se extiende, normalizando paulatinamente lo que poco tiempo antes hubiera parecido exagerado. Imagínese tener acceso a todas las aplicaciones de la nube de forma permanente y universal (o a algunas de ellas, las que más le guste y pueda pagarse llegado el caso) a través de un pequeño chip personalizado, a modo de tarjeta sim, insertado en su cerebro... Tener acceso ilimitado a bases de datos, conocimientos específicos de cualquier área del saber, conexión directa con software que pudiera resolver cualquier problema en cualquier ámbito en tiempo real, potenciadores de su visión tanto de día como de noche, poder aumentar su agudeza auditiva a capricho, incluso sintonizar ondas de radio o sonidos de frecuencias inaudibles al oído humano, control total sobre cualquier malestar o sensación de dolor, disfrutar de experiencias virtuales con sensación de realidad en cualquier momento, poder comprender cualquier lengua y que su interlocutor le entienda a usted sin esfuerzo, conexión al GPS y a mapas actualizados con sólo un parpadeo, y qué decir de poder realizar video llamadas, acceder a juegos en red, a las redes sociales etc. sin preocuparse de quedarse sin datos o sin batería, más que de lo que se preocupa ahora de comer.

Tal vez sea usted un tipo raro con alergia al progreso, sin ambición alguna por poder hacer mucho más de lo que le permite su naturaleza, con una gran capacidad para sobrellevar con total naturalidad y resignación sus limitaciones personales, enfermedades y mermas fruto de la edad o de un accidente. Aun así, debería preocuparse por el lugar que usted o sus hijos ocuparían en una sociedad donde el resto del mundo tuviera un nivel excepcional de competencia, interconexión, conocimientos, control de su organismo, capacidad de cálculo..., al que usted y los suyos no podrían acceder. Ser un paria entre súper humanos no parece una vida muy halagüeña.

Porque de eso se trata, de ser súper hombres o súper mujeres capaces de sobrepasar los límites del diseño genético y del ritmo que marca la evolución de forma natural, o por lo menos eso es lo que nos venden. Nos acercaríamos sin lugar a dudas a nuestro yo ideal, al menos al yo ideal que de nosotros mismos tenemos ahora, desconozco a lo que aspirarán los «súper hombres» del futuro. Pero está claro que en alguna medida seríamos más sabios y poderosos, pudiendo hacer más cosas y con mayor eficacia que ahora, con capacidad para mantener un contacto social permanente a capricho, pudiendo encontrar altos niveles de satisfacción a través de una alta estimulación en cualquier faceta o área de la vida, pudiendo tener más experiencias y más intensas, así como reducir muchísimo los niveles de sufrimiento tanto físico como psicológico.

El problema es que tal vez estemos pasando algunas cosas por alto..., cosas que ya sabemos de nosotros mismos y que serían los «efectos secundarios» de esta «evolución», pero que no aparecen en la «letra pequeña» porque el contrato aún no ha sido escrito, y cuando lo tengamos delante daremos al 
botón de «aceptar» sin leerlo, tal y como ya hacemos, porque si queremos tener las mismas habilidades que el resto no nos quedará otra.

\section{SENSACIÓN DE NORMALIDAD}

Lo primero que queremos denunciar es que no parece claro que vayamos a sentirnos mejor porque seamos súper hombres o súper mujeres desde la perspectiva actual, pues ese sentimiento surge de la comparación con otros que necesariamente han de estar por debajo, pero si todos disponemos de los mismos dispositivos lo más que traerá el futuro, como acabamos de señalar, será la angustia de no querer ser menos que el resto y tratar de lograr a toda costa que nosotros y nuestros hijos disfruten de tan increíbles mejoras, de las últimas versiones y actualizaciones que salgan al mercado, tal y como ocurre ahora con dispositivos mucho menos determinantes. Del mismo modo que no nos hace sentirnos «inmortales o eternos» saber que, hace cien años, la esperanza de vida era casi la mitad que ahora, tampoco es probable que los súper humanos del futuro se sientan como tales porque sus capacidades superen con creces las nuestras ¿Qué efecto tiene en nuestros hijos decirles que nosotros no tuvimos internet ni teléfonos móviles? Más allá de cierta perplejidad o sorpresa, no parece que el dato les haga disfrutar más de sus vidas, pero ni siquiera a nosotros en la medida que ya nos hemos acostumbrado a su uso cotidiano, recordar el pasado nos hace más felices en el presente. Siempre viviremos como normal lo que nos sea dado y serán las mejoras inalcanzables las que marquen el horizonte de los grandes sueños de la humanidad. Tal vez los neandertales soñaran con ser y vivir como nosotros, pero para nosotros su sueño no es más que nuestra cotidiana realidad y por ello no nos genera ninguna satisfacción extra.

\section{SÚPER HOMBRES CON PIES DE BARRO}

Otro problema es la disparidad entre la imagen ideal de lo que creeremos ser y que ya nos venden, y lo que de verdad seamos. A día de hoy, en la sociedad occidental, ya somos muchos los que tenemos problemas para identificar lo que verdaderamente somos, para aceptar nuestras limitaciones y relacionarnos de forma madura y equilibrada con lo que nos gustaría ser, con las imágenes de un yo ideal muy determinado por patrones culturales. Aceptar la imagen que nos devuelve el espejo cuando no nos gusta es complicado y un buen maquillaje una solución fantástica para acercarnos a lo que verdaderamente nos gustaría. Ser el campeón del mundo en una especialidad deportiva es un sueño que se hace más asequible si mejoras tu rendimiento con algún tipo de sustancia. Ser una estrella de la canción si no tienes voz es posible si utilizas un procesador que convierte tu graznido en un cántico celestial. Pero ¿es nuestro verdadero rostro el que vemos súper maquillado, es de verdad el mejor deportista el que se ha dopado, es real que tengas una hermosa voz cuando ha sido sintetizada 
por un dispositivo? A día de hoy, supongo que la mayoría de nosotros todavía responderemos de forma negativa a todas estas cuestiones, así pues, por una sencilla regla de tres, no es cierto que vayamos a convertirnos en súper hombres o súper mujeres cuando hagamos un montón de cosas gracias a los dispositivos artificiales que incorporemos a nuestro cerebro u otras partes del cuerpo.

No seremos súper hombres ni súper mujeres, seremos personas igual de limitadas que ahora, sólo que estaremos súper asistidos por prótesis y herramientas artificiales. Y tal vez seamos incluso más limitados porque es innegable que lo que no ejercitamos se atrofia o ni siquiera se desarrolla, perdiendo así habilidades y destrezas que de otro modo tendríamos a pleno rendimiento. A mí ahora me costaría hacer bien una raíz cuadrada cuando de chaval las hacía a gran velocidad y sin problemas, pero son demasiados años ya haciéndolas con calculadora...Y no nos vale el argumento de que desarrollaremos nuevas destrezas porque apretar los botones de una calculadora no aumenta nuestra capacidad de cálculo, ni supone una gran mejora intelectual. Es cierto que durante siglos las máquinas, incluidos los primeros dispositivos de I.A., han sustituido al hombre en las tareas más pesadas y rutinarias que le robaban tiempo y energía, liberándolo para tareas superiores que requerían la exclusiva complejidad y potencia de su cerebro. Pero el verdadero cambio que está trayendo el vertiginoso avance de la I.A. es precisamente la progresiva alteración de dicho principio. Cada vez las máquinas inteligentes asumen la realización de tareas más complejas y sofisticadas, relegando nuestra actividad a meras acciones mecánicas y rutinarias de puesta en marcha y parada de determinados procesos y de cierta supervisión y valoración de los resultados, algo que de hecho cada vez nos compete menos. No se nos pueden vender simultáneamente que la I.A. llegará a igualarnos y/o superarnos, y que aun así nosotros seguiremos estando "por encima». La I.A. no avanza para hacernos mejores, avanza para mejorar ella misma, abaratar costes a la industria y para satisfacernos como consumidores de servicios. Poderosos dispositivos insertados en nuestro cerebro serán como súper muletas que atrofiarán parte de nuestra «musculatura mental» por falta de uso y difícilmente podremos abandonarlas por el coste que tendría vivir sin las mismas.

\section{La ANGUSTIA VITAL DE SER EN FUNCión DE LO QUE PODAMOS PAGAR}

Que no seamos verdaderamente súper humanos o que incluso la parte exclusivamente neural del futuro ciborg sea «menos» de lo que pudiera haber sido al no haberse desarrollado adecuadamente, no es el único problema. Para muchas personas ya es difícil diferenciar su verdadera identidad de la imagen que proyectan de sí mismo en función de los objetos que poseen (casas, coches, ropa de marca, relojes, dispositivos electrónicos...), lo que en nada es comparable a lo que nos espera. La incapacidad para aceptar las propias limitaciones podría tornarse en una fuente de angustia insoportable para una humanidad incapaz de asumirlas. En la actualidad estamos obligados a enfrentarnos casi a diario con nuestras limitaciones personales y aun así nos 
cuesta, pero hablamos de generaciones de personas que estarán acostumbradas a «superarse» a base de comprar actualizaciones, sin experiencia alguna de resignación, ni de esfuerzo o sacrificio porque lo que no se pueda o no se sea se resolverá fácilmente comprando la aplicación o el dispositivo adecuado. Tener que renunciar a maravillosas mejoras sólo alcanzables a través del mercado generará un sentimiento de «injusticia o envidia social», pero nada que ver con la auto exigencia o la aceptación de la verdadera naturaleza limitada de uno mismo.

Hablamos de una angustia vital ya que quiénes somos depende en gran medida de lo que somos capaces o no de hacer. Nuestras destrezas y limitaciones personales conforman una parte importante de nuestra identidad. Mi hijo con Síndrome de Down no sería la misma persona ni para él mismo ni para todos lo que le queremos si, de golpe y porrazo, se viera libre de su discapacidad intelectual. Todo cambiaría radicalmente. Hablamos por tanto de la angustia de dejar de ser uno mismo, de perder la situación relativa en nuestro grupo de referencia, de resultar un desconocido tanto para ti como para los demás.

Y curiosamente, afirmaciones que durante siglos han sido símbolo de una honda sabiduría carecerán de sentido en el futuro ¿Qué «verdad (sobre nosotros mismos) será la que nos haga libres» si lo que seamos dependerá de lo que cada uno se pueda pagar? ¿Cómo asumir que «sólo sé que no sé nada» si accedo mentalmente a la Wikipedia? ¿Cómo aceptar que «si te comparas con los demás, te volverás vano y amargado» o que «no es más rico quien más tiene, sino quien menos necesita», cuando la vida y la identidad personal dependerán de aquellas aplicaciones a las que puedas o no acceder para diferenciarte de los demás?

\section{AdICTOS DE POR VIDA}

Con lo dicho hasta ahora será más fácil comprender la envergadura del problema de dependencia profunda y a distintos niveles que desarrollaremos en torno a estos avances. Estos futuros dispositivos serán irresistibles manjares de versatilidad y potencia para cualquiera que los pruebe y, en consecuencia, adictivos a más no poder. A modo de ejemplo, si ahora no veo bien la televisión y me pongo las gafas de lejos disfruto de una visión nítida y clara, pero si me las quito una hora después ya no veo lo poco que veía bien antes de ponérmelas. Multipliquemos este efecto por... ¿un millón? Así será como nos sentiremos, así será cómo seremos tras el uso continuado de los apósitos neurales que la I.A. traiga a nuestras vidas.

Como ya hemos señalado, sin esos dispositivos perderemos estatus social e identidad personal porque seremos incapaces de hacer casi nada y los necesitaremos para llegar a la altura de los demás. Viviremos con angustia no disponer de los mínimos avances de los que el resto disfruta y con la atrofia de muchas de nuestras funciones mentales, un posible fallo de dichos dispositivos traerá un grado de disfunción tal que difícilmente podremos reconocernos, la diferencia entre lo que «seamos» y podamos hacer con o sin ellos será 
como pasar de golpe a un estado pseudo zombi. Será el trágico «ser o no ser» de Shakespeare, pero llevado a una dimensión muy distinta de a la que originalmente se refería el autor inglés. Creo que son fáciles de imaginar los niveles de dependencia y adicción a los que podríamos llegar. Pagaremos lo que haga falta para ser lo que creamos ser y lo que nos gustaría llegar a ser antes que enfrentarnos al oscuro pozo de la angustia del no ser y a un traumático sentimiento de incompetencia.

\section{TOXICIDAD FUNCIONAL}

Por ahora no vamos a inquietarnos por posibles «virus informáticos» en nuestro cerebro, o por el acceso externo a datos íntimos (pensamientos, recuerdos, deseos...) o por la publicidad, cookies etc. Esperemos que la legislación nos porteja y sigamos sólo valorando lo que de nosotros sabemos. Nos sigue quedando una cuestión en el aire de calado tan incierto como inquietante, la posible toxicidad funcional que estos dispositivos puedan suponer en el entramado de actividad armónica y global que en gran medida es nuestra mente.

Como ya dijimos al inicio, poco sabemos a día de hoy de la naturaleza de nuestra actividad consciente y por tanto es difícil saber cómo se podría ver afectada por una invasión de datos y actividad creada y sostenida por dispositivos artificiales que interaccionarán de forma masiva y directa con diferentes centros neurales. Pero sí sabemos que, precisamente, la actividad consciente parece ser sostenida y creada por la acción conjunta y coordinada de muchos de estos centros, según los objetivos y tareas requeridas en cada caso. La suma de ambos factores, el nivel de ignorancia que a día de hoy tenemos respecto a nuestra actividad consciente y la complejidad y armonía requerida para ponerla en marcha, sugiere que no parece que vaya a ser fácil prever los efectos secundarios que sobre dicha actividad cerebral vaya a tener el uso a largo plazo de distintos apósitos cerebrales.

Atendiendo una vez más a lo que sabemos de situaciones similares, aunque sean cualitativa y cuantitativamente mucho más precarias, vamos a ir señalando algunos de esos posibles efectos secundarios relacionados con posibles disfunciones de nuestra actividad psíquica.

Sabemos desde hace tiempo que la sobrecarga de estimulación sensorial y cognitiva genera estrés, cansancio, problemas de atención, concentración y alteraciones del sueño, de la conducta y emocionales (Goldberger, 1993; Hatayama, Takayama \& Komatsu, 1970; Lipowski, 1974)². Pues bien, en el futuro ciborg estaremos expuestos como ahora a los estímulos externos de la realidad de nuestro entorno y a los que internamente genere nuestra mente (pensamientos, recuerdos...) pero también a los que la red y las distintas aplicaciones cerebrales pondrán $24 \mathrm{~h}$ al día y 365 días al año a

2 De hecho, es una forma de tortura y por ello conlleva serias dificultades éticas para su investigación en la actualidad. 
nuestra disposición, alterando probablemente las entradas e interacciones de los primeros. Sin lugar a dudas, inquieta pensar el coste que para la salud mental pudiera tener soportar tal cantidad de información en una constante e impredecible interacción.

Por otro lado, el cerebro está diseñado para relacionarse con la realidad externa, pero en el futuro tendremos acceso ilimitado a una estimulación artificial interna de experiencias virtuales que podría superar con creces la primera. Muchos niños ya prefieren jugar al futbol con sus consolas que en la realidad. La mayoría de las personas no miran su entorno cuando viajan en el metro o en el autobús, están centrados en sus teléfonos móviles. Es fácil prever que buscaremos con ahínco experiencias virtuales positivas, huyendo de las realidades monótonas y negativas que nos rodeen. ¿Qué vida querremos vivir, dónde encontraremos más fácilmente el placer, la distracción, las satisfacciones anheladas..., en la árida y limitada realidad física o en «a la carta» e ilimitada realidad virtual? ¿Durante cuánto tiempo podrá un cerebro así de bombardeado diferenciar la realidad externa de la virtual?

Nuestro desarrollo cognitivo se basa en la adquisición de experiencias individuales. Nuestra consciencia es un sistema abierto, diseñado para tantear alternativas y para hacerse sabio de sí mismo según la realidad que a cada uno le toca vivir (Núñez, 2012). Pues bien, todo esto será algo que claramente entrará en riesgo sin que sepamos cómo afectará al funcionamiento global del sistema. En el futuro ciborg seremos «sabios» de lo global, pero no de nosotros mismos. La base de datos de la auto gestión personal estará vacía. No tendrán valor ni cuantitativa ni cualitativamente las experiencias individuales sino la información global, universalmente compartida. En alguna medida ese fenómeno ya ha empezado, antes nos buscábamos unos a otros por lo que nos aportábamos en nuestra originalidad, ahora sólo nos diferenciamos en la medida que estamos o no al día de lo que circula por las redes. Todos sabemos lo mismo y si no, lo compartimos, no son nuestras experiencias individuales lo que importa y lo que nos comunicamos sino lo que la nube nos brinda.

Nuestras capacidades de aprendizaje y de adaptación tienen una relación directa y positiva con la exploración, la improvisación, el ensayo-error, la implicación y el grado de actividad desempeñado y todo ello implica cambios en la arquitectura cerebral y la funcionalidad psicológica. Dicho desarrollo del entramado neural se verá afectado en gran medida ya que pasaremos a un no aprendizaje o a un aprendizaje extremadamente pasivo, pues todo nos será dado o seremos meros ejecutores de instrucciones. Sobre todo, adquiriremos estrategias y competencias por «copia y pega», pero apenas usaremos datos individuales, ni generaremos estrategias propias. Ahora todos podemos hacer de electricista en casa siguiendo los vídeos tutoriales de youtube. Ni siquiera hace falta memorizar ni tomar notas ya que sabemos que siempre van a estar a nuestra disposición, mejorando y actualizándose constantemente, sólo tenemos que seguir pasivamente los pasos que se nos indican.

Así pues, no parece que la humanidad vaya a ser más feliz, ni sea tan fácil concebirla como mejor, más desarrollada ni mucho menos formada por súper personas. Del mismo modo que los desinfectantes y los antibióticos 
vinieron para salvarnos la vida y ahora sabemos que su uso en exceso merma la capacidad de nuestro sistema inmunológico ¿qué efecto tendrá en nuestra delicada y sofisticada actividad consciente toda esta asistencia e interferencia artificial? ¿qué será de una actividad consciente inundada de datos de bases artificiales y de realidad virtual, que no resolverá activamente casi nada, que apenas gestionará la individualidad, sin identidad personal clara, que dependerá angustiosamente de apósitos y asistentes virtuales, que no vivirá determinadas experiencias y apenas afrontará sufrimiento alguno...? ¿Hasta qué punto la persona oculta tras el súper ciborg será más sabia y más libre que el homo vulgaris actual?

\section{LA SOCIEDAD DE LOS CIBORGS}

Y aunque no es nuestro campo, creemos conveniente señalar alguno de los retos sociales que traerán estos cambios y que también ya se vislumbran.

Claramente las relaciones personales virtuales aumentarán frente a los contactos cara a cara, incluso la interacción con sistemas artificiales de tipo androide ajustados a nuestros gustos y necesidades ocuparán una gran relevancia, lo que mermará nuestro desarrollo social como individuos al reducirse nuestras relaciones a los contactos a "capricho». Ahora una parte importante de nuestra batalla vital consiste en enfrentar la soledad, la incorporación, la ruptura y la permanencia en los grupos sociales en los que nos toca vivir. En el futuro no tendremos que afrontar el aburrimiento, ni la soledad, ni la dificultad de la gestión de los conflictos en persona y será más fácil eludir la propia responsabilidad gracias a la distancia o el anonimato, y el coste de la pérdida será menor gracias al acceso instantáneo a otros grupos y personas a nivel mundial.

Disminuirá drásticamente la variabilidad social, si ya es difícil ser original y distinto en un grupo de diez, parece improbable que nadie se aventure a intentar serlo frente los "grupos humanos» de millones de personas hiper conectadas, cuando además podremos asumir distintas personalidades entre las ya estandarizadas en la aplicación correspondiente.

El progreso estará más determinado que nunca por las modas y no por las verdaderas necesidades de una humanidad cada vez más perdida y angustiada en no quedarse al margen de las utilidades de las que disfrute el resto.

Nos enfrentaremos a una drástica revisión de nuestro sistema de valores ¿será infiel el cónyuge que mantenga relaciones sexuales en un espacio virtual con otro ciborg? ¿Qué maldad real hay en la crueldad desarrollada en un mundo virtual o ejercida sobre seres artificiales (androides)? Y la además responsabilidad jurídica de los individuos habrá de ser revisada también por la difícil diferenciación entre lo que podría ser un fallo de las aplicaciones neurales, o un acto "deliberado» en sentido clásico.

Las diferencias entre las clases sociales se volverán dramáticas ya que podrían acarrear fácilmente diferencias insalvables en niveles funcionales y ejecutivos de todo tipo. 
Aquellas corporaciones que controlen los sistemas más vendidos en el mercado tendrán un poder difícilmente controlable por gobiernos y sociedades dependientes de ellos.

Dejaremos de ser creadores de conocimiento, al menos los individuos de a pie, la sabiduría estará en manos del sistema ¿quién se atreverá a contradecir las conclusiones extraídas de los sistemas que trabajen con Big Data?

\section{REFERENCIAS BIBLIOGRÁFICAS}

Chalmers, D. (1996). The conscious mind: In search of a fundamental theory. New York, NY US: Oxford University Press.

Crick, F. (1994). The Astonishing Hypothesis: The Scientific Search for the Soul. New York, NY US: Scribner.

Crick, F., \& Koch, C. (1990). Towards a neurobiological theory of consciousness. In Seminars in the Neurosciences (Vol. 2, pp. 263-275). Saunders Scientific Publications.

Dennett, D. C., \& Weiner, P. (1991). Consciousness explained. New York, NY, US: Little, Brown and Co.

Goldberger, L. (1993). Sensory deprivation and overload. In L. Goldberger, S. Breznitz, L. Goldberger, S. Breznitz (Eds.). Handbook of stress: Theoretical and clinical aspects, 2nd ed (pp. 333-341). New York, NY, US: Free Press.

Hatayama, T., Takayama, T., \& Komatsu, H. (1970). Studies on sensory overload: I. Part 2. Effect of sensory overload and sensory deprivation upon physiological functions: Results of polygraphic records. Tohoku Psychologica Folia, 23(3-4), 73-83.

Kurzweil, R. (2000). The age of spiritual machines: When computers exceed human intelligence. Baltimore, MD, US: Penguin Books.

Kurzweil, R. (2005). The singularity is near: When humans transcend biology. Baltimore, MD, US: Penguin Books.

Lipowski, Z. J. (1974). Sensory overloads, information overloads and behavior. Psychotherapy And Psychosomatics, 23 (1-6), 264-270.

Núñez, J. P. (2013). La consciencia: de misterio a objetivo científico muy preciado. Revisión de diversas concepciones sobre la mente humana. Tendencias 21. Tendencias de las religiones. Revista electrónica de ciencia, tecnología, sociedad y cultura. http:// www.tendencias21.net/La-consciencia-de-misterio-a-objetivo-cientifico-muypreciado_a14761.html

Núñez, J. P. (2014). Más que monos y máquinas. Pensamiento: Revista de Investigación e Información filosófica (6), 839-854.

Núñez, J. P. (2015). Libertad o determinismo neurológico. Cuenta y Razón (2a Etapa, n ${ }^{\circ}$ 34), 51-58. ISSN: 1889-1489. Versión electrónica (2017) en: https://blogs.comillas. edu/FronterasCTR/2017/09/06/libertad-fenomenologica-fundamentos-neurologicos/

Searle, J. R. (1992). The rediscovery of the mind. Cambridge, MA, US: MIT Press.

Universidad Pontificia Comillas (Madrid)

jnunez@comillas.edu

Juan Pedro Núñez Partido

[Artículo aprobado para publicación en enero de 2019] 